\title{
Internacionalização, letramento crítico e extensão: a experiência democrática do English Club na UFMS/CPTL
}

\author{
Fabrício Tetsuya Parreira Ono ${ }^{1}$ \\ João Pedro Fernandes Gomes²
}

\section{Resumo}

Este trabalho busca apresentar algumas reflexões sobre o projeto de extensão English Club: On-campus conversation. A ação tem por objetivo oferecer um ambiente livre e democrático para prática da conversação em língua inglesa, até então inexistente na cidade de Três Lagoas. O projeto tem por bases epistemológicas $e$ ontológicas trabalhos recentes no que se refere à internacionalização (SANTOS; GUIMARÃESIOSIF, 2013) e letramento crítico (DUBOC, 2014; MENEZES DE SOUZA, 2011), que possibilitaram a relativização cultural e rompimento com ideias hegemônicas por meio das discussões propostas. Após descrição de alguns encontros, é ressaltada a importância de encarar a metodologia enquanto processo contínuo na obtenção de resultados significativos, bem como as contribuições que o English Club proporcionon à formação dos professores envolvidos.

Palavras-chave: Conversação em língua inglesa. Formação de professores. Democratização

\footnotetext{
${ }^{1}$ Universidade Federal de Mato Grosso do Sul.

2 Universidade Estadual Paulista "Júlio de Mesquita Filho".
} 


\section{Introdução}

Este artigo busca discutir uma ação de extensão intitulada English Club: On-campus conversation realizada na UFMS/CPTL, que tem como fim promover encontros quinzenais gratuitos voltados para o exercício oral da língua inglesa. Este projeto é aberto tanto para membros da universidade quanto da comunidade externa e é uma possibilidade para que os participantes possam praticar/exercitar seus conhecimentos em língua inglesa por meio de rodas de conversa direcionadas a partir de um tema.

Para tanto, enfatizamos os princípios epistemológicos e ontológicos que dão suporte para a ação em questão e o modo como o trabalho foi sendo (re)construído desde seu início até o momento da escrita deste texto. Ainda, apresentaremos exemplos das atividades promovidas durante os encontros do projeto e as perspectivas futuras dessa ação.

\section{English Club: On-Campus Conversation: Um breve histórico}

As origens do English Club datam de meses antes de seu estabelecimento enquanto projeto de extensão validado pela universidade. Surgiu como trabalho final da disciplina Conversação em Língua Inglesa, ofertada como optativa para alunos dos últimos anos do curso de Letras, e teve como espaço de origem a própria sala de aula. Assim, o que podem ser considerados seus primeiros encontros-teste foram realizados como tarefa final da disciplina.

A proposta, que se tornou uma missão para os acadêmicos, surgiu pela observação do professor, futuramente coordenador do projeto, de que não havia na cidade e nem mesmo no campus um espaço no qual as pessoas pudessem praticar/exercitar seus conhecimentos em língua inglesa. Na verdade, havia um desejo implícito da criação de tal espaço expresso pelo discurso dos falantes de inglês da região, que alegavam saber a língua, mas não ter onde colocá-la em ação de forma gratuita e desprovida da formalidade dos cursos de idiomas.

Dessa carência, surge uma missão para os grupos de alunos, que tivesse como objetivo promover um encontro com participantes de dentro e fora do curso de Letras, de semestres e áreas diversos, ou mesmo membros da comunidade externa pudessem se reunir 
para praticar a conversação em inglês. Planejada ao longo de todo o semestre, a tarefa poderia ser concretizada de inúmeras formas, desde que viabilizasse atividades que priorizassem a prática oral na língua-alvo, como vinha acontecendo em todas as aulas da disciplina.

Embora as atividades apresentadas pelos grupos ainda fossem incipientes, não atingindo o destaque esperado para a prática oral da língua inglesa, o resultado foi significativo o bastante para instigar os alunos-organizadores a extrapolarem as fronteiras da disciplina. Mais do que isso, forneceu insumos valiosos para discussões e reflexões que desencadearam ações posteriores e aprimoraram a abordagem metodológica do grupo. Aos poucos, assim, o novo projeto foi se consolidando a partir de bases teóricas e observações empíricas.

Tudo isso culminou na criação do projeto de extensão em pauta, cujos princípios teóricos e filosóficos, bem como exemplos práticos de seu funcionamento, serão discutidos nas próximas seções.

\section{Por que democratização?}

O acesso a situações de ensino e aprendizagem ou prática de língua estrangeiras parece bastante limitado no contexto em questão, principalmente, no que se refere a iniciativas que promovam situações articuladas entre a sociedade e os "espaços" públicos. É por este viés que entendemos que a oportunidade apresentada pelo projeto destacado neste artigo pode ser entendida como uma oportunidade democrática de acesso a encontros de práticas e uso de uma língua estrangeira, o que parece ainda ser algo restrito a institutos de idiomas ou professores particulares do idioma.

Por isso, ressaltamos que nosso entendimento acerca de ações democráticas está relacionado ao processo e não a um fim, ou seja, temos buscado abrir as portas de um espaço público para possibilitar que a prática de uma língua estrangeira não fique limitada/restrita àqueles que podem pagar por isso em espaços privados. 


\section{Por que internacionalização?}

Se a democratização se coloca como um objetivo no ensino de língua inglesa no âmbito do English Club, abre-se caminho para um processo relacionado, ainda mais amplo em escopo: o de internacionalização. Por internacionalização, entendemos que seja um processo de mão dupla, com ações locais que reverberem em outras ações e que contribuam para o desenvolvimento de cidadãos conscientes de que vivemos em um mundo onde a troca de saberes e experiências não pode se limitar apenas ao contexto em que vivemos.

Por consequência, configura-se aqui a internacionalização também como um ato de resistência à "marketização" do ensino superior. Se o movimento de internacionalização não é novo no Brasil, tendo origens em tempos coloniais, os moldes de exclusão social do passado se intensificam consideravelmente na política neoliberal.

Da mesma forma que as classes dominantes que, até o século XIX, obtinham educação na Europa antes mesmo das massas terem direito à alfabetização, o acadêmico de hoje, muito embora tenha acesso à educação, se encontra encurralado num jogo de poderes. Não só formado pelas alianças estreitas entre governo e mercado, que imprimem interesses extra-educacionais às universidades, como também pela globalização, que transforma políticas globais em locais numa marcha constante rumo à homogeneização (SANTOS; GUIMARÃES-IOSIF, 2013).

Em outras palavras, o ensino é construído por parâmetros não primariamente educacionais, mas, sim, econômicos, transformando o aprendiz num cliente e o ensino num bem comerciável. Desconsideram-se as diversidades e necessidades da maioria da população, e alterna-se o foco para as exigências do mercado. Isso se torna prejudicial no sentido que

Quando se globaliza, a Universidade não é mais um 'espaço onde as contradições no país podem expressar sua identidade e onde podemos defender interesses coletivos, expressados na superação da desigualdade social e econômica e emancipação política e cultural para a maioria de seus habitantes' (ALMEIDA; SOUZA; MANCINI, 2008, p.195 apud SANTOS; GUIMARÃES-IOSIF, 2013, p. 19, tradução nossa ${ }^{3}$ ).

\footnotetext{
3 Tradução livre do original: "When you globalize, the University is no longer a 'space where the contradictions in the country could express their identity and where we can defend collective interests, expressed in overcoming social inequality and economic, political and cultural emancipation for the majority
} 
Nesse sentido, concordamos com Santos e Guimarães-Iosif (Op. cit., p. 19, tradução nossa) quando dizem, no contexto de globalização, ser necessário que a sociedade civil "se mantenha unida e use esse momento não apenas para ir de encontro aos interesses de mercado, mas também fortalecer o Estado em favor dos interesses das minorias que são excluídas desse processo"4.

No entanto, entendemos que pequenas ações, como exemplo do projeto aqui apresentado, possam corroborar para o que Ono (2016) entende como processo de internacionalização:

As modificações causadas pelo processo de globalização manifestam-se, além da economia, nas questões políticas, sociais, culturais, educacionais e tecnológicas. Por isso, os mecanismos de comunicação precisaram ser revistos e geraram uma intensificação nas redes de interação entre as comunidades e economias. Desta forma, houve um grande impacto na produção de conhecimento (ONO, 2016, p. 106).

Por ser o English Club um espaço democrático, aberto e, em especial, sem fins lucrativos, é possível criar condições para um contexto de ensino e aprendizagem de línguas livre de amarras mercadológicas padronizantes. Contribui ainda localmente para a redução dos riscos que envolvem a internacionalização da educação superior, dentre eles a falta de domínio da língua inglesa por acadêmicos, a supervalorização de produtividade e competição e a colonização implícita pelos países do norte (SANTOS; GUIMARÃES-IOSIF, 2013).

Por fim, abrimos espaço para que se consolide o verdadeiro propósito da internacionalização, relacionado à "cooperação acadêmica, solidariedade institucional e liberdade de pensamento" (DIAS SOBRINHO, 2010 apud SANTOS; GUIMARÃES-IOSIF, 2013, tradução nossa $\left.{ }^{5}\right)$.

of its inhabitants'" (ALMEIDA; SOUZA; MANCINI, 2008, p.195 apud SANTOS; GUIMARÃES-IOSIF, 2013, p. 19).

${ }^{4}$ Tradução livre do original: "to stand together and use this moment not only to meet market interests, but also to strengthen the state in favour of the interests of minorities who are excluded from this process" (SANTOS; GUIMARÃES-IOSIF, 2013, p. 19).

5 "academic cooperation, institutional solidarity, and freedom of thought" (DIAS SOBRINHO, 2010 apud SANTOS; GUIMARÃES-IOSIF, 2013, p. 15). 


\section{Letramento crítico}

Considerando a proposta supracitada de relativização cultural e rompimento com relações hegemônicas impostas pelo mercado da educação, seria impossível nos afastarmos do letramento crítico num contexto como o do English Club. Mais ainda considerando que, enquanto grupo de conversação, ele tem por base a democratização da língua e rompimento com perspectivas engessadas de que há espaços "corretos" para a prática/exercício da língua inglesa.

Além de a conversação ser mais propícia ao surgimento de debates calorosos, a abertura do espaço universitário a toda a cidade inevitavelmente atrai pessoas de contextos diversos, com repertório e experiências distintas, configurando uma multiplicidade de posicionamentos que fomentam o trabalho com as diferenças, tendo como base epistemológica o letramento crítico. De acadêmicos e docentes do curso de Letras e de outros cursos - o que, por si só, já seria um público consideravelmente heterogêneo - a professores e alunos do ensino regular, e mesmo participantes não vinculados a nenhuma instituição de ensino, é inevitável o embate de opiniões e, por vezes, o conflito com o outro.

Num mundo de construções identitárias tão fluidas e multifacetadas, que não mais aceitam categorizações óbvias, tal exercício de contato com o outro nunca foi tão importante na formação crítica do cidadão. Isso porque o letramento crítico assume papel ativo na redução daqueles conflitos justificados pelas diferenças individuais. Faz isso ao mostrar ao aprendiz que essas diferenças existem e muni-lo de ferramentas para que possa tornar um aparente problema em novas possibilidades de significação. Forma-se, assim, um indivíduo preparado para o contato com a diversidade social do mundo.

Por essa perspectiva, concordamos com Menezes de Souza (2011) quando diz que uma das tarefas primordiais do letramento crítico é colocar o ser em formação em contato aprofundado com o outro. Afinal, como mostra ao citar Freire, não é falando que se aprende, mas, sim, ouvindo ao outro, o não-eu, para que se saiba quanto do $e \boldsymbol{u}$ se identifica e quanto se opõe a ele. Em suma, a proposta é ouvir-se escutando, uma vez que o processo de construção da própria identidade está longe de ser individual e independente.

O English Club acaba se tornando um espaço favorável não apenas ao letramento crítico, mas à ressignificação constante da identidade dos sujeitos participantes. Em termos 
práticos, essa abordagem metodológica surge em diversos níveis dos encontros: tem início na seleção dos membros de um grupo, que leva estrategicamente a diversidade como critério, e se expande até os questionamentos presentes no material didático elaborado, que sempre conduzem a respostas não prontas. É por essa proposta que se faz possível estabelecer pontes culturais entre a cultura do aprendiz e a do outro e, mais do que isso, possibilitar a ele ter novas perspectivas sobre a própria cultura.

Como exemplo, um encontro no qual isso se deu de forma significativa será descrito aqui. Ao discutirmos Tastes and Stereotypes (gostos e estereótipos), os vídeos escolhidos versavam sobre estrangeiros que mostravam reações a músicas e alimentos do Brasil, que após a exibição tinham como objetivo fomentar os seguintes questionamentos: por que eles tendem a pensar assim? O que em sua cultura se difere da nossa que pode causar essas diferentes opiniões? Todas as pessoas dessa nacionalidade pensam dessa forma? E as suas opiniões sobre as comidas/músicas apresentadas são as mesmas de todo o seu grupo?

Os questionamentos supracitados estavam previstos tanto no roteiro de discussão pós-texto disponibilizado para cada grupo, de forma mais estruturada, como nos conversation cards, fichas com perguntas "sortidas" que podem ser utilizadas como input para discussão a qualquer momento do encontro.

Exercício semelhantemente pautado pelo letramento crítico aconteceu no encontro sobre Asian Culture, no qual um dos tópicos mais evidentes foi whitewashing, a prática comum em Hollywood de atribuir personagens asiáticos a atores brancos. Para o trabalho, escolhermos por trazer não só um vídeo informativo sobre essa prática produzido por um jornal americano, mas também trazer logo em seguida entrevistas com pessoas do Japão dando opinião sobre algo que os afeta mais do que a qualquer um. Foi possível fugir da armadilha de muitos materiais didáticos de língua inglesa, que acabam

elegendo uma perspectiva, no caso, a perspectiva dominante, tratando a diversidade de valores e costumes como se estes fossem universais, homogêneos, ou seja, válidos para outros povos ou até mesmo válidos para todas as pessoas de uma mesma nação (DUBOC, 2015, p. 214).

O projeto traz, assim, a diversidade de perspectivas e identidades como forma de crescimento mútuo, ampliando as possibilidades de (re)significação dos participantes dentro daquilo que consideram verdade. Prioriza, portanto, relações horizontais entre 
nações e culturas, tratando-as sem atribuição de valores, evitando relações hierárquicas que podem resultar em opressão.

\section{Construindo e desconstruindo práticas}

Todos os pressupostos que nortearam o acontecimento do English Club desde o princípio tomaram forma por meio das atividades propostas. O processo, entretanto, se deu de forma gradual, numa abordagem metodológica em constante atualização. Esta seção se dedica a descrever o funcionamento do projeto, englobando as reflexões que levaram às reformulações.

No primeiro encontro oficial do projeto já cadastrado como extensão, os exercícios foram pensados de forma que funcionassem para um público até então desconhecido. Juntamente com a atividade de warm-up "two truths and a lie", dedicada à integração dos membros participantes, o tema, exercise pills, propunha uma discussão com a qual acreditávamos que todos se relacionariam: a invenção científica de pílulas que substituiriam o exercício físico.

A partir dessa proposta, foi elaborado um roteiro de conversação, disponível como Apêndice A, que propunha exercícios fomentadores de debate. Tais atividades seriam realizadas em grupos de seis participantes, que teriam conhecimento do encontro por ampla divulgação promovida em redes sociais, como mostra a figura 1. 


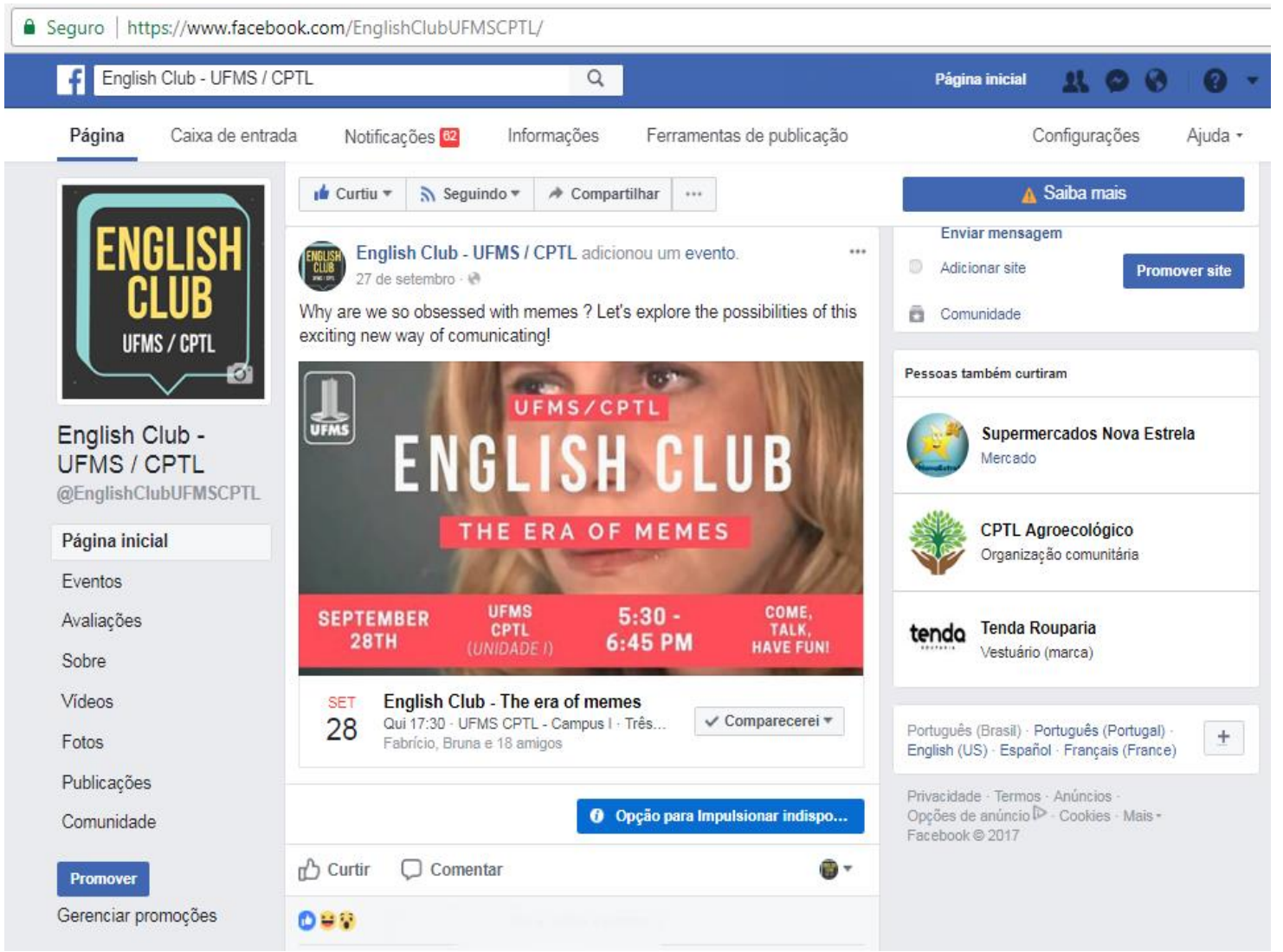

Figura 1: modelo de divulgação do projeto via redes sociais.

O primeiro encontro acabou fornecendo diversos insumos para reflexão acerca de nossa proposta metodológica. Apesar de o warm-up ter funcionado como atividade de integração e os grupos terem tamanho apropriado, percebemos a predominância de atividades que envolviam as habilidades de leitura e escrita (talvez por serem as mais trabalhadas nos contextos de ensino em que os graduandos organizadores do projeto estavam envolvidos, como o estágio obrigatório em escolas públicas). No primeiro encontro, portanto, a proposta principal do grupo de conversação não foi atendida: criar condições favoráveis para o exercício oral da língua inglesa.

Como fator agravante da falta de diálogo, os diferentes níveis de proficiência criaram obstáculos na comunicação, fazendo com que alguns participantes se propusessem a traduzir o texto todo para outros menos proficientes, consumindo mais tempo que o previsto. O tema escolhido, Exercise pills, também se mostrou perigosamente específico, resultando em desconfortáveis períodos de silêncio total nos grupos após certo tempo.

A partir do segundo encontro, portanto, sentimos a necessidade de rever as atividades e organização propostas inicialmente. Começando pela divisão prévia dos grupos 
por proficiência, com base no Quadro Comum Europeu de Referências para Linguas: tendo recebido um teste de nivelamento por e-mail alguns dias antes do próximo encontro, os participantes puderam ser divididos em grupos mais condizentes com seu nível, reduzindo obstáculos no que se refere à compreensão mútua. Também foi possível, por esse ajuste, direcionar o mesmo texto com complexidade adaptada para cada nível, mantendo a coerência temática, mas facilitando o acesso às informações. Fichas de vocabulário relacionado ao tema do encontro também foram disponibilizadas, ajudando principalmente em encontros que exigiam termos específicos de alguma área (por exemplo, alimentação ou viagens).

$\mathrm{Na}$ tentativa de tornar a interação entre os grupos mais dinâmica, elaboramos conversation cards, pequenas cartas empilhadas na mesa de cada grupo que contém perguntas ou minidesafios relacionados ao tema do dia. Por não exigirem a leitura do texto para sua realização, elas se mostraram uma solução tanto para os períodos de silêncio, funcionando como recurso "de emergência" quando não havia debate, como para alunos menos proficientes ou desinteressados no texto escolhido, que poderiam conversar abertamente sobre o tema de forma mais rápida e direta.

Também passamos, na metade de cada encontro, a trocar alguns membros e realocá-los em novos grupos, de forma a trazer uma pessoa diferente, com outras experiências e opiniões, na tentativa de revigorar uma conversa já desgastada. Vale ressaltar que essa movimentação é sempre feita de forma estratégica, percebendo carências específicas em cada grupo e quais membros seriam mais apropriados para supri-las.

Quanto ao tema dos encontros, de início foi feita uma pesquisa com os participantes para indicarem tópicos de seu interesse que gostariam de ver explorados em encontros posteriores. Porém, mais adiante, percebemos que não era o tema em si um impedimento para que a discussão fluísse, mas o modo como ele era trabalhado. Foi nessa etapa que o letramento crítico entrou como facilitador no English Club, indicando como temas aparentemente simples como comidas ou cultura asiática poderiam ser levados em direções mais significativas do que aparentam, como descrito na seção anterior deste artigo.

Da mesma forma, se a proposta era proporcionar um ambiente que permitisse uma prática menos tradicional do inglês, não faria sentido utilizar apenas textos escritos como encadeadores de conversação. Foi assim que recorremos à multimodalidade a partir do encontro três, superando a visão de texto como produção escrita e trazendo imagens, 
vídeos, emojis, e mesmo performances musicais ao grupo. Após recepção positiva dos participantes, que disseram ter mais facilidade em compreender a língua inglesa quando há o auxílio de recursos visuais e sonoros, e não só palavra, o ecletismo de modalidades é parte recorrente dos encontros.

Faz-se pertinente lembrar que todos os aperfeiçoamentos metodológicos não aconteceram de forma repentina, mas gradualmente, por meio de análises e reanálises ao longo dos encontros. Mesmo algumas soluções a princípio acabam se transformando em desafios tempo depois: a separação de grupos por proficiência, mesmo tendo funcionado num momento inicial em que não conhecíamos os alunos, acabou se mostrando como um fator secundário em seu desempenho nas atividades, uma vez que estavam também sujeitos à timidez, familiaridade com o tema e configuração do grupo.

Conhecer melhor a sala de aula e atuar como pesquisadores dentro dela acabou, como em qualquer contexto de ensino, sendo a melhor alternativa para tomar melhores decisões pedagógicas. Dessa forma, tentamos representar tal experiência por meio da figura 2, na qual sintetizamos a importância das reformulações metodológicas na construção do conhecimento.

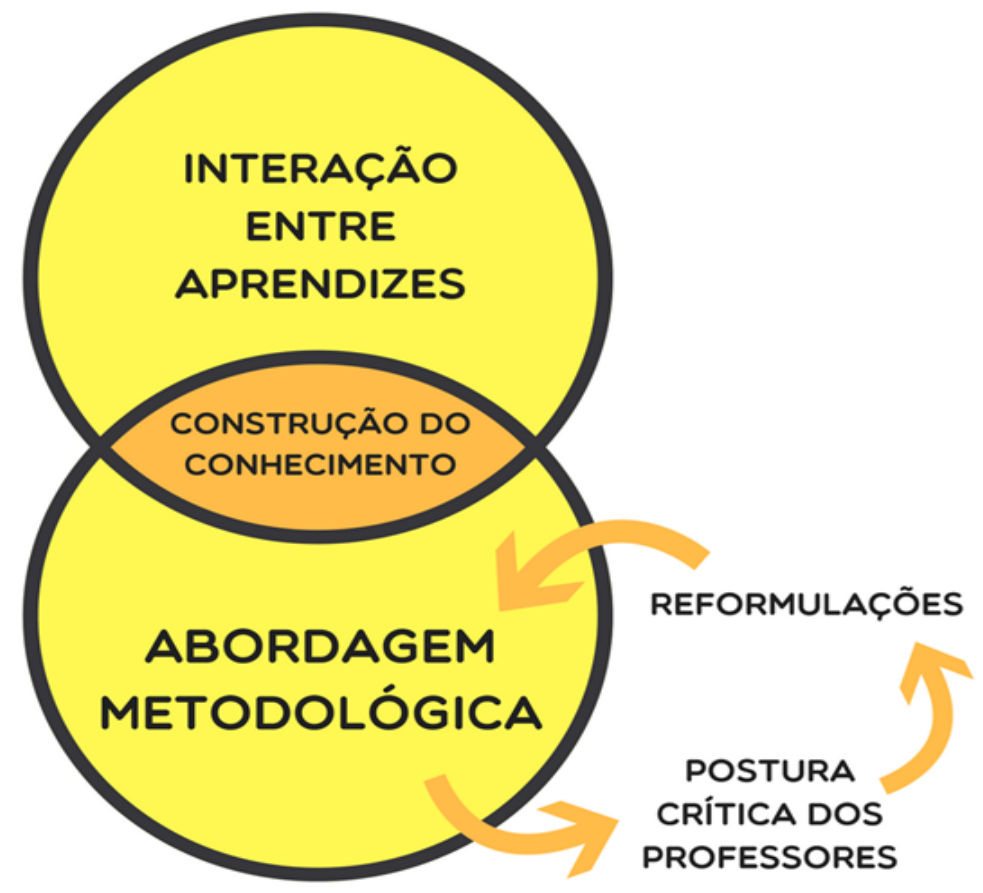

Figura 2: o papel da abordagem metodológica na construção do conhecimento. 
Hoje, já tendo realizado treze encontros do English Club, entendemos que o processo de construção e reconstrução de práticas deve ser encarado como um continuum, e não algo que possa ser planejado e hermetizado para toda a duração de uma proposta a longo prazo como essa. É a postura crítica constante que permitiu diminuir as barreiras entre o aprendiz e a construção do conhecimento por meio da língua-alvo, objetivo maior do projeto.

\section{Considerações finais}

Este artigo buscou viabilizar uma discussão acerca de projetos de extensão e suas possibilidades diante de um cenário no qual possamos democratizar o acesso à prática de língua inglesa em contextos públicos e gratuitos. Além disso, mostrar de que forma podemos expandir nossos conceitos sobre ações que influenciam no processo de internacionalização da educação.

Contudo, vale ressaltar que trouxemos também como pano de fundo desta ação um processo que inclui a formação de professores de língua inglesa que contemple não apenas o ensinar e aprender uma língua estrangeira, mas que contribua para uma educação linguística crítica, de forma que seja ancorado em outros elementos que subjazem a educação em nível superior.

$\mathrm{Na}$ próxima edição desta ação de extensão, teremos a contribuição de English Teaching Assistants, que poderão contribuir com outros olhares para que possamos construir e reconstruir nossas práticas no contexto apresentado, assim como poderemos expandir e aumentar o número de encontros mensais. 


\section{Referências}

DUBOC, A. P. Letramento Crítico nas brechas da sala de aula de línguas estrangeiras. In: TAKAKI, N. H.; MACIEL, R. F. (Org.). Letramentos em terra de Paulo Freire. Campinas: Pontes, 2014, p. 195- 207.

MENEZES DE SOUZA, L. M. T. Para uma redefinição de letramento crítico: conflito e produção de significação. In: ARAUJO, V. A.; MACIEL, R. F (Org.). Formação de professores de línguas: ampliando perspectivas. Jundiaí: Paco Editorial, 2011.

SANTOS, A. V.; GUIMARÃES-IOSIF, R. M. The internationalization of higher education in Brazil: a marketing policy. Journal of Contemporary Issues in Education, v. $8, \mathrm{n}^{\circ} 1$, 2013, p. 15-27. Disponível em:

$<$ https://journals.library.ualberta.ca/jcie/index.php/JCIE/issue/view/1496>. Acesso em 14 nov. 2017.

ONO, F. T. P. A ressignificação do global por atitudes locais na implementação do programa Inglês sem Fronteiras na UFRR: algumas experiências. In: SARMENTO, S.;

ABREU-E-LIMA, D. M.; MORAES FILHO, W. (Org.). Do Inglês sem Fronteiras ao

Idiomas sem Fronteiras: a construção de uma política linguística para a

internacionalização. Belo Horizonte: Editora UFMG, 2016, p. 105-123. 


\section{Apêndice A - Exemplo de roteiro de conversação}

\section{ENOLSH (UFMS/CPTL)}

CLUB

UFMS / CPTL

Meeting 10 (10/05/2017) - 2000's culture

WARM-UP: Guess the song

Can you identify these 2000's songs just a few seconds in?

Now, watch the video and discuss the question:

\section{TEXT 1 - Top 10 Cartoons of the 2000s}

Discuss the questions below with your partners:

- How many cartoons from the video do you know?

- Which one is your favorite? Give three reasons to justify your love.

- What other cartoons you used to watch on TV during the 2000's?

- Why do you think the cartoons are similar in American and Brazilian TV channels?

- How do you feel about Brazilian cartoons not being common on TV?

- Would you like Brazil to produce more cartoons? What kind of themes could they talk about?

- How is television and cinema changed comparing the 2000's and nowadays? 


\section{TEXT 2 - Women Wear Early 2000s Fashion For A Day}

\section{Read the text below and discuss the questions:}

1. Are you familiar with Buzzfeed? What do you think about their videos?

2. Buzzfeed is used to post a lot of videos on YouTube that intend to make people more confident and comfortable with their bodies and identities. Do you think that's important? How? For whom?

3. Why do you think the women on the video were so afraid to dress like 2000's celebrities?

4. How would you react if people started wearing fashion from the 2000's again?

4. Do you ever feel some kind of pressure to dress like nowadays fashion?

5. Why do you think fashion changes through time? Isn't it just a practical thing?

6. What do clothes represent to you?

7. Do you consider fashion a kind of art? Why (not)? 


\section{Abstract}

This paper aims to present some reflections upon the extension project English Club: On-campus conversation. The action has the objective of providing a free and democratic space for practicing conversation in English language, nonexistent in the city of Três Lagoas until then. The project has recent works regarding internationalization (SANTOS; GUIMARÃESIOSIF, 2013) and critical literacy (DUBOC, 2014; MENEZES DE SOUZA, 2011) as epistemic and ontological basis. Those theories allowed working with cultural relativism and breaking hegemonic ideas through the proposed discussions. After the description of some meetings, we emphasize the importance of considering the methodology a continuous process to achieve meaningful results, as well as the contributions that the English Club had in the formation of the teachers involved.

Keywords: Conversation in English language. Teacher formation. Democratization

Recebido em: 23/12/2017.

Aceito em: 14/06/2018. 